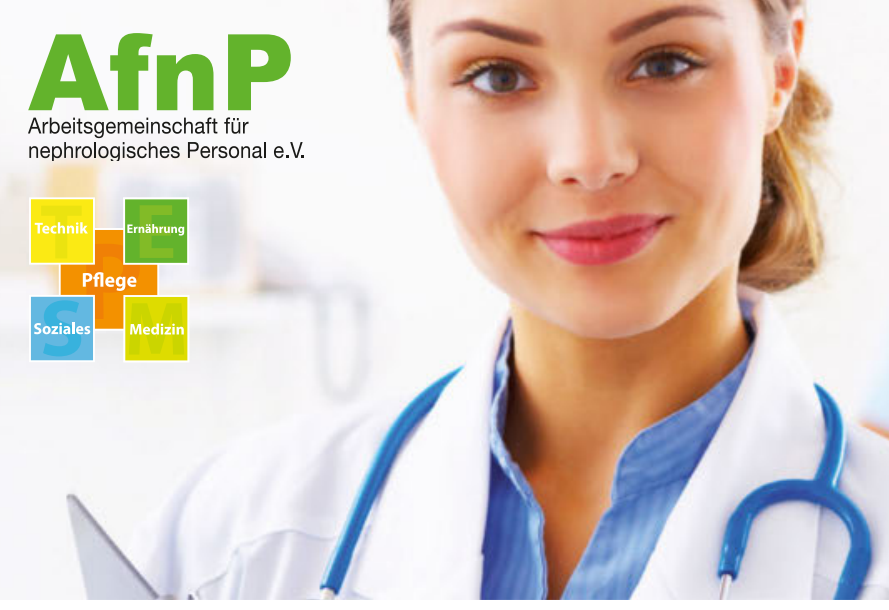

\title{
Arbeitsgemeinschaft für nephrologisches Personal e. V.
}

Die AfnP e. V. wurde als gemeinnütziger Verein 1978 gegründet. Wir vertreten die Interessen des gesamten nephrologischen Teams.

\section{Wir sind}

kompetent in allen Fragen der Nephrologie.

\section{Wir organisieren} unabhängige Fort- und Weiterbildungen - regional und überregional.

\section{Wir arbeiten}

mit allen relevanten Fachgesellschaften und der Politik zusammen.

\section{Wir transportieren} die Ideen unserer Mitglieder an die richtigen Adressen.

\section{Wir sind für Sie da}

\section{Geschäftsstelle \\ Käppelesweg 8 \\ 89129 Langenau

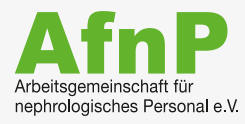 \\ Telefon: 07354/22933 \\ Fax: 07354/7540 \\ info@afnp.de | | www.afnp.de}

Verantwortlich für die AfnP-Fachgesellschaftsseiten: Marion Bundschu, Ulm (V.i.S.d.P.)

\section{Vorstand der AfnP:}

Marion Bundschu (1. Vorsitzende)

Hans-Martin Schröder (2. Vorsitzender) Roswitha Nicklas (Schatzmeisterin) Ilona Adler (Schriftführerin)
Jahresbeitrag 30 Euro für examinierte Pflegekräfte und Fachpflegekräfte sowie Medizinische Fachangestellte, Techniker, Diätassistenten, Ärzte und viele andere.

\section{Bildungsgutschein}

Sie erhalten einen Bildungsgutschein über 40 Euro für unsere Veranstaltungen und die unserer Kooperationspartner.

\section{Dialyse aktuell Dialyse}

Sie erhalten bis zu 10-mal jährlich die Fachzeitschrift Dialyse aktuell frei Haus.

\section{Fachinformationen} unabhängige Informationen, frei von wirtschaftlichen Interessen

\section{Ansprechpartner}

Bundesweit sind unsere Ländervertreter für Sie da.

\subsubsection{7}

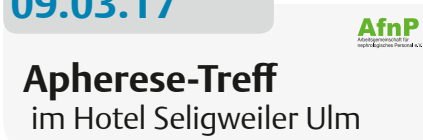

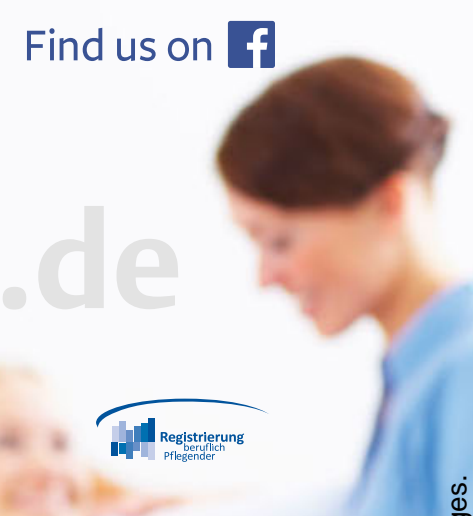

i

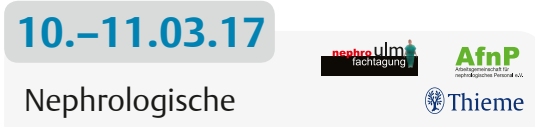

Fachtagung Ulm

01.04.17

Tagesseminar im Museum Fürth

Geschichte der Nephrologie

24. -25.11 .17$

AfnP-Symposium in Fulda

interessante Workshops und

Vorträge aus der Nephrologie

Freitag, 24.11.17

Forum Technik

forumtechnik

Samstag, 25.11.17

\section{Peritonealdialyse Basic Day}

\section{Buch „Dialyseshunts"}

Erweiterte 2. Auflage zu beziehen Die am 03.08.2016 erschienene 2. Auflage des Buches "Dialyseshunts“ von Hrsg. Prof. Gerhard Krönung, Wiesbaden, ist u.a. über die AfnP bestellbar: über www.afnp.de oder bei der AfnP-Geschäftsstelle für 29,99 Euro + 3,50 Euro (Porto und Versand in (D)).

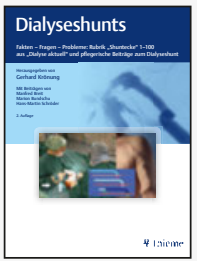

